\title{
Influences on Consumers' Recycling Intentions of Compact Fluorescent Lamps-Mercury as a Factor
}

\author{
David M. K. Treumann ${ }^{1} \&$ Jonna Holland ${ }^{1}$ \\ ${ }^{1}$ College of Business Administration, University of Nebraska at Omaha, Nebraska, USA \\ Correspondence: Jonna Holland, Department of Marketing and Management, 6708 Pine Street, MH303T, \\ University of Nebraska at Omaha, Omaha, NE 68182, USA. Tel: 1-402-554-3156. E-mail: \\ jholland@unomaha.edu
}

Received: August 14, 2013

Accepted: September 6, 2013

Online Published: November 12, 2013

doi:10.5539/ijms.v5n6p175

URL: http://dx.doi.org/10.5539/ijms.v5n6p175

\begin{abstract}
The purpose of the current study is to understand consumers' behavioral intentions in situations involving both positive and negative potential impacts on the environment. The case of energy efficient Compact Fluorescent Lamps (CFLs) with their potential for mercury pollution is an example of this type of trade-off. Past studies have confirmed the usefulness of the Theory of Reasoned Action for identifying the antecedents influencing recycling rates, however, none have looked at situations where conflicting environmental trade-offs were involved. Stepwise regression analysis was used to develop a core model which explains $\mathrm{R}^{2}=.561$ of the intention to recycle. Significant antecedents include the peer group subjective norm of recycling CFLs (Beta=.661), the attitude towards recycling of CFLs (Beta=.417), the attitude towards the overall environmental friendliness of CFLs (Beta $=-.344$ ), and the attitude towards the number of sites available for recycling of CFLs (Beta $=.212$ ). Adding the impact of past recycling behavior increases the model's explanatory power to .726. Important policy implications result from the finding that the number of people who would 'always or usually' recycle CFLs increased to $90 \%$ by enhancing the convenience of recycling. A significant managerial implication results from the contradictory findings that the attitude towards mercury is not significantly correlated with intentions to recycle, however the attitude towards the environmental friendliness of CFLs was negatively related to recycling intentions. This potentially indicates that there is a lack of understanding of the net positive impact of CFLs and there is potential confusion about the related environmental trade-offs. Recommendations for policy and marketing responses are suggested.
\end{abstract}

Keywords: compact fluorescent lamps, CFLs, recycling, mercury, Theory of Reasoned Action

\section{Introduction}

Consumers are often faced with conflicting information about products and their environmental impact. Ecologically friendly and sustainable properties like energy efficiency often come at the price of drawbacks in other areas. Adverse side effects from overall beneficial changes in consumption patterns and behaviors may only surface later in the product life-cycle. A consequence that is not immediately obvious and understandable is the increased need for recycling when changing from low-tech to high-tech solutions. Using Compact Fluorescent Lamps (CFLs) is a case in point, since CFLs contain mercury to produce light with improved energy efficiency. The consumer's decision to purchase CFLs is accompanied by the burden to dispose of the bulbs properly or risk contributing to mercury pollution. Encouraging recycling as the default behavior instead of disposing of CFLs with normal household waste is therefore a priority to achieve the sought after sustainability.

The objective of this study is to determine whether the attitude towards the mercury content of Compact Fluorescent Lamps (CFLs) is significantly correlated with the behavioral intention to recycle CFLs and to establish which attitudes and norms are good predictors of said intention. This is done by applying the basic concepts of the Theory of Reasoned Action. This theory states that behavior is the outcome of behavioral intentions which are influenced by attitudes and subjective norms. Apart from the consumer's attitude towards mercury other attitudes and norms were tested to determine the important predictors of the intention to recycle and create a relevant model to gain insights into antecedents that could be influenced to improve recycling rates of CFLs. 
Improvements in recycling rates of CFLs are even more desirable than improvements in general recycling rates since most recycling consists of changing consumer behavior from the status quo (not recycling) to a positive impact resulting from recycling. For example, the change from not recycling to recycling paper results in fewer trees cut and less energy expended, however, there are no toxins released from a sheet of paper if it ends up in a landfill instead of being recycled. In the case of CFLs the change is from the unnecessary release of toxic agents, (mercury), to recycling the CFLs and thus containing the mercury. How does the additional burden of recycling CFLs or potentially releasing toxins factor into consumers' decision to recycle this type of energy efficient technology? This is an important question for marketers of CFLs as well as those attempting to increase consumers' sustainable behavior.

\section{Background}

Understanding the consumer's decision to purchase and recycle CFLs is important for environmentalists, public policy makers, and all those involved in the CFL industry, and understanding this energy saving technology is the first step. CFLs contain a small amount of mercury which is necessary for normal operation (Alvarez-Caicoya, Cosme-Torres, \& Ortiz-Rivera, 2011). For CFLs sold in the U.S. the National Electrical Manufacturers Association (NEMA) prescribes in its voluntary commitment a maximum of 4 to $5 \mathrm{mg}$ of mercury per light bulb depending on the wattage (National Electrical Manufacturers Association, 2010). The mercury is not emitted during normal operation but is released when the bulb breaks, for example, in landfills, in incinerators, or due to mishandling. Some "green" CFLs have been introduced to the market which use a reduced amount of mercury. This class often fulfills the requirements of the Toxicity Characteristic Leaching Procedure (TCLP). If the CFLs produce less than $0.2 \mathrm{mg}$ mercury per liter in a leakage test, they are considered non-hazardous. However, there are also vapor releases from the CFLs which can approach $1 \mathrm{mg}$. These are not part of the criteria of the TCLP, however, this emission is still relevant if the reduction of mercury emissions is the goal (Li \& Jin, 2011). Nevertheless, all compact fluorescent lamps are not automatically treated as hazardous waste and for individual consumers, are not regulated by the federal universal waste regulations (Standards for Universal Waste Management, 2012; US EPA, 2013). Therefore, for consumers, the lamps are not federally prohibited from being discarded with normal household trash. However, states or local municipalities are free to enact laws that do prohibit this. Throughout the US, practices range from areas where no regulations beyond the federal guidelines exist, to states such as California where recycling of CFLs is mandatory (Nebraska Department of Environmental Quality, 2011; Mercury-Containing Products That Are Hazardous Wastes When Discarded, 2013).

To understand the environmental trade-offs of CFLs compared to incandescent bulbs, the possible release of mercury from CFLs must be viewed in relation to possible reductions of mercury emissions stemming from electric energy generation. The primary source of mercury pollution in producing electricity is by coal-fired power plants since mercury occurs naturally in coal and is released during burning of coal for electricity production (US Environmental Protection Agency and US Department of Energy, 2010). Therefore, the lifetime mercury emission of a comparable incandescent light bulb is obviously higher in areas that utilize electricity produced by coal. Incandescent light bulbs use more electrical power and due to this more coal has to be burned to operate them. The US national electricity mix consists of $44.5 \%$ electricity that was produced in plants fueled by coal. For the national average, the reduction in mercury lifetime emissions is at about 3.8 to $6.6 \mathrm{mg}$ for every two incandescent $75 \mathrm{~W}$ bulbs replaced with CFLs. This is a conservative estimate which expects every CFL destined for disposal to break and release all the contained mercury. However, according to a more realistic model that takes into account that parts of the mercury remain in the lamp even if it is broken, the net reduction is at about 6.8 to $8.8 \mathrm{mg}$ of mercury on average for every two traditional bulbs replaced with CFLs (Dunmire et al., 2003, pp. 16-18). Obviously, the net mercury reduction is significantly increased if CFLs are recycled.

In the area where the respondents reside, $69.1 \%$ of electricity is produced from coal. This was calculated with the help of the web application 'Power Profiler' which is an online calculator for the electric energy mix that at the time of calculation relied on data from the year 2009 (US EPA, n.d.). For the study area, about $8 \mathrm{mg}$ of mercury emissions are avoided if two incandescent 75W lamps are replaced with CFLs (Dunmire et al., 2003, p. 18, Figure 4).

Recycling rates of CFLs in the U.S. are rather low. Exact data is difficult to obtain since there are diverse options employed in the recycling process - ranging from mail-in or in-store return, to drop-off at collection sites. A study on the usage and recycling of CFLs in Maine from 2009 cited numbers from as low as $2 \%$ nationally to $6.7 \%$ for Lane County, Ore., (Wagner, 2009, p. 5). However, these numbers could vary greatly across the country considering the fact that the disposal of CFLs with household trash is outlawed in some jurisdictions and no regulations exist in others. Convenience and knowledge are identified as important influences on recycling rates 
(Dahab, Gentry, \& Su, 1995). Accordingly, recent research recommends expanding the number of free drop-off locations and refocusing education from communicating the general need of recycling to a more practical approach that points the public to specific locations (Wagner, 2011).

\section{Literature Review}

Many studies over the last twenty years have demonstrated the value of the Theory of Reasoned Action for understanding the consumer's intention to recycle (Biswas, Licata, McKee, Pullig, \& Daughtridge, 2000, p .94; Dahab et al., 1995; Goldenhar \& Connell, 1993; Nameghi \& Shadi, 2013; Park \& Ha, 2012; Schultz \& Oskamp, 1996; White \& Hyde, 2012). The Theory of Reasoned Action states that behavior is the outcome of behavioral intention which is influenced by the relationship between attitudes and subjective norms related to the behavior (Ajzen \& Fishbein, 1980). Additionally, past behavior is a variable that typically explains a significant amount of variance in behavioral intentions (Ajzen, 2002). This variable is also highly correlated if the topic of the study is recycling (Dahab et al., 1995). Therefore, past behavior was also elicited in this study to see whether this is also the case for recycling of CFLs.

In addition to the general recycling studies mentioned above, some studies have looked specifically at consumers' attitudes towards CFLs. Park and Lee (2013) report that while positive perceptions of CFLs relate to higher usage, there were also significant differences in these perceptions and behaviors related to consumers' socio-demographic characteristics. Overall, adoption of CFLs was related to consumers' perceptions of visual comfort, aesthetics, cost, and performance issues such as flickering, slow start-up time, and compatibility with common light fixtures.

However, no studies to date have looked at the influence of the trade-off of potential negative and positive environmental impacts of CFLs and the intention to recycle. Given the current promotion of CFL adoption by manufacturers, energy companies, governmental entities and environmental advocates, it is important to understand consumer attitudes towards these issues.

Based on the studies mentioned above, it was expected that attitudes towards recycling in general, attitudes towards CFLs, and perceptions of subjective norms regarding recycling would all influence the intention to recycle. Furthermore, research shows that effort moderates the relation between attitudes and behavior (Dahab et al., 1995; Schultz \& Oskamp, 1996), therefore it was expected that effort would be negatively related to intention to recycle. Since the mercury content in CFLs is the primary motivation for recycling them, it was decided to also measure consumers' attitudes towards mercury.

Past behavior expresses acquired knowledge about the recycling process and, therefore, should predict behavioral intentions (Biswas et al., 2000, pp. 94-95). It is theorized that habituation plays a part in this. However, Ajzen (2002) refutes this argument and proposes that a good model should be able to sufficiently describe the intention without relying on past behavior because attitudes should express the influence of knowledge on the underlying beliefs sufficiently. The relative completeness of a model should therefore show itself in whether past behavior significantly adds explained variance.

\section{Proposed Model:}

Behavioral Intention to Recycle CFLs results from the relative weight a consumer gives to attitudes towards the Mercury in CFLs, Environmental Impact of CFLs, Recycling in General, Recycling CFLs, Effort Required to Recycle, Perception of Subjective Norms, and Past Recycling Behavior

\section{Method}

\subsection{Research Instrument}

A questionnaire was developed using the Theory of Reasoned Action. This questionnaire was extended to include past behavior and perceptions concerning the degree of effort required to conduct behaviors. The behavioral intention with regard to disposing of CFLs is the dependent variable. It was elicited by asking respondents to choose from a five-step frequency scale that ranges from 'always', 'usually', 'sometimes', 'seldom' to 'never' to complete the following sentence, "When I have to dispose of CFLs in the future, I will __ recycle". Thus the likelihood of the act of recycling of CFLs in the future is discovered and the behavioral intention determined. The distribution of behavioral intentions given the reality of available recycling options in the current situation forms the baseline for later comparisons with a focus on the influence of effort that has to be expended to recycle CFLs.

Six attitudes were looked at using Likert-Scales. First, the attitude towards the overall environmental friendliness of CFLs was obtained. This has two aspects; on the one hand, energy savings and, on the other, the necessary 
mercury content (however this wasn't asked until the end-see below). Second, the attitude towards the recycling of CFLs is uncovered. It reveals whether one believes one should recycle. Third, the attitude towards recycling in general, for example of paper, cans, and so on, was determined. Fourth, the attitude concerning the number of sites that offer recycling options for CFLs was established. Fifth, the attitude towards the effort to recycle CFLs was measured. Sixth, two questions addressed the respondents' perception of subjective norms towards recycling, again, using Likert-Scales. Lastly, after all other questions, the attitude towards the mercury in CFLs was gauged; first assessing the perception of the quantity of mercury in CFLs and second, the perceived level of harm to the environment. The references to mercury were placed last on the questionnaire to avoid a possible priming of the responses.

Another three items were included to investigate the perceived effort with regard to recycling CFLs. The first item asked about the perceived effort of having to drop-off CFLs at only one location as is often the case with the disposal of hazardous substances at one central specialized facility. The second item asked about a situation more or less equal to the current situation in the study area of having different locations available for recycling across the city. The last item represents a situation closer to the ideal: being able to return CFLs at every store that sells new ones. These three levels of effort were measured in terms of frequency of recycling as indicated by always, usually, sometimes, seldom or never.

Finally, a question was added to see if past behavior with regard to recycling CFLs significantly adds explained variance to the intention to recycle CFLs. To measure this behavior, again, a frequency scale was used.

\subsection{Sample and Data Collection}

The survey consisting of 25 questions was distributed online by means of social networking sites as well as distributed offline to a convenience sample without the promise of any incentive for participating. As mentioned earlier, significant variations exist in the regulations governing recycling of CFLs depending on state, city and county jurisdiction. To avoid those confounding issues and the related variations in consumer understanding of the applicable laws, etc. the decision was made to draw the sample from a single metropolitan area. Ajzen and Fishbein (1980) note that the Theory of Reasoned Action is best applicable if the behavior is volitional. Therefore, a mid-sized Midwestern metropolitan area with no regulations regarding CFL disposal was selected for the study. In this way, the behavioral intentions towards recycling were hypothesized to be related only to the attitudes, subjective norms and past behavior rather than regulatory mandates.

The complete data set entails the answers of 151 participants. However, due to the of nature sampling on the Internet, there were responses from participants not living in the specified metropolitan area. These had to be excluded to not distort the validity of the study with regard to locally available recycling options and regional laws about recycling CFLs. Therefore, 91 valid responses were retained of which approximately half were collected online and half offline. Furthermore, not every participant answered all questions. For a couple of questions the number of answers is lower. However, there are at least 65 complete cases and thus a sufficient number of data points are available for every question. For these cases, $78.5 \%$ of participants have used or are using CFLs while $20 \%$ have not.

\subsection{Statistical Analysis of Data}

The following statistical model describes the basic relationship between the dependent variable and the independent variables (Lindquist \& Sirgy, 2006, p. 293):

$$
B=f(B I)=f\left(A_{1}{ }^{*} w_{1}+\ldots+A_{n} * w_{n}+S N_{1} * w_{1}+\ldots+S N_{n} * w_{n}\right)
$$

Hale, Householder, and Greene (2002) propose to use an additive relation to analyze the data, as was done in this study:

$$
B=B I=A_{1}{ }^{*} w_{1}+\ldots+A_{n}{ }^{*} w_{n}+S N_{1} w_{1}+\ldots+S N_{n}{ }^{*} w_{n}
$$

Finally, to calculate the empirical evaluation weights (w) the statistical model was transferred into a multiple regression analysis. Beta weights from this analysis were used to determine the weights (w).

$\mathrm{B}=$ behavior, here, recycling of CFLs

$\mathrm{BI}=$ behavioral intention to conduct said behavior

$\mathrm{A}=$ attitudes towards: Mercury in CFLs, Environmental Impact of CFLs, Recycling in General, Recycling CFLs, and Effort Required to Recycle

$\mathrm{SN}=$ subjective norms concerning the recycling of CFLs

$\mathrm{w}=$ empirically determined weights 


\section{Results}

\subsection{Characteristics of Respondents}

The survey yielded 91 relevant responses from the study area. Of these, $\mathrm{N}=65$ complete sets are available for analysis. Concerning gender, 37 of the relevant survey-takers were female (57\%) and 28 male (43\%). The average age for the relevant sample is 26 years with data ranging from 18 to 52 years.

\subsection{Attitude towards Mercury in CFLs}

Contrary to expectations, the attitude towards the mercury content in CFLs is not significantly correlated with the intention to recycle (Beta $=-.169, \mathrm{p}=.164)$.

\subsection{Extended Model}

The extended model contains all the attitudes and norms that were included in this study as promising predictors for the behavioral intention to recycle compact fluorescent lights. The explained variance is at $58.7 \%$ with this model. It contains all seven independent variables - two subjective norms and five attitudes. Analysis of Variance demonstrates that this model is significant at $\mathrm{p}<.001$.

\subsection{Core Model}

The core model was created from all the attitudes and norms by utilizing stepwise regression to find a more parsimonious model. The goodness of fit for the core model in terms of explained variance is at $56.1 \%$ of the variance of the dependent variable adjusted for the number of variables in the model $\left(\mathrm{R}^{2}\right.$ adjusted $\left.=.561\right)$. It contains four independent variables and the dependent variable. The mean of -.62 for the dependent variable corresponds to a value between "usually" at -1 and "sometimes" at 0 . The subjective norm concerning recycling of CFLs in the respondent's peer group was the antecedent with the strongest effect on the dependent variable. Its single variable coefficient of determination, not taking into account any other variable, is at $\mathrm{R}^{2}=.324$. The other three variables that add significantly to the core model, were the attitude towards recycling of CFLs, the attitude towards the overall environmental friendliness of CFLs, and the attitude towards the number of sites where recycling of CFLs is available. The explained variance in the behavioral intention of the core model is very close to the explained variance of the extended model while the number of salient antecedents was reduced from seven to four. The attitude towards the overall environmental friendliness of CFLs is negatively correlated with the behavioral intention. All the other variables in the core model are positively correlated with the behavioral intention. Analysis of Variance shows that this model is significant at $\mathrm{p}<.001$.

Table 1. Descriptive statistics of variables in the core model

\begin{tabular}{llll}
\hline & Mean & Std. Deviation & $\mathrm{N}$ \\
\hline $\begin{array}{l}\text { Norms concerning recycling of CFLs in the peer } \\
\text { group }^{\mathrm{a}}\end{array}$ & .37 & 1.084 & 65 \\
$\begin{array}{l}\text { Attitude towards recycling of CFLs } \\
\text { Attitude towards the overall environmental }\end{array}$ & 1.83 & 2.096 & 65 \\
friendliness of CFLs & 1.11 & 1.382 & 65 \\
$\begin{array}{l}\text { Attitude towards number of sites where recycling of } \\
\text { CFLs is available }\end{array}$ & -1.18 & 2.061 & 65 \\
Behavioral Intention to Recycle CFLs & & & \\
\hline
\end{tabular}

a. Independent Variable.

b. Dependent Variable.

Table 2. Analysis of variance (ANOVA) ${ }^{\mathrm{b}}$

\begin{tabular}{llllll}
\hline Core Model & Sum of Squares & $\mathrm{df}$ & Mean Square & $\mathrm{F}$ & $\mathrm{p}$ \\
\hline Regression & 49.030 & 4 & 12.257 & 21.407 & $<.001^{\mathrm{a}}$ \\
Residuals & 34.933 & 60 & .573 & & \\
Total & 83.385 & 64 & & & \\
\hline
\end{tabular}

a. Independent Variables: (Constant), Norms concerning recycling of CFLs in the peer group, Attitude towards recycling of CFLs, Attitude towards the overall environmental friendliness of CFLs, Attitude towards number of sites where recycling of CFLs is available.

b. Dependent Variable: Behavioral Intention to Recycle CFLs. 
Table 3. Coefficients ${ }^{\mathrm{a}}$

\begin{tabular}{|c|c|c|c|c|c|}
\hline \multirow[t]{2}{*}{ Core Model } & \multicolumn{2}{|c|}{ Unstandardized Coefficients } & \multicolumn{3}{|c|}{ Standardized Coefficients } \\
\hline & $\mathrm{B}$ & Std. Error & Beta & $\mathrm{t}$ & $\mathrm{p}$ \\
\hline Constant & -.836 & .152 & & -5.502 & $<.001$ \\
\hline $\begin{array}{l}\text { Norms concerning recycling of CFLs in the } \\
\text { peer group }\end{array}$ & 697 & .090 & .661 & 7.757 & $<.001$ \\
\hline Attitude towards recycling of CFLs & .227 & .049 & .417 & 4.665 & $<.001$ \\
\hline $\begin{array}{l}\text { Attitude towards the overall environmental } \\
\text { friendliness of CFLs }\end{array}$ & -.284 & .073 & -.344 & -3.886 & $<.001$ \\
\hline $\begin{array}{l}\text { Attitude towards number of sites where } \\
\text { recycling of CFLs is available }\end{array}$ & .117 & .047 & .212 & 2.500 & .015 \\
\hline
\end{tabular}

a. Dependent Variable: Behavioral Intention to Recycle CFLs.

\subsection{Past Behavior}

Adding past behavior significantly increases the explained variance adjusted for the number of predictors. The addition of past behavior results in a $17.2 \%$ increase over the more parsimonious core model to $73.3 \%$. (The extended model $\mathrm{R}^{2}$ adjusted improves by $13.9 \%$ to $72.6 \%$ ).

\subsection{Effort as an Influencing Factor}

The effort that has to be expended to recycle CFLs is influencing the intention to recycle. Not only does the attitude towards the number of sites where recycling of CFLs is offered have a significant effect on the intention to recycle $($ Beta $=-.344, \mathrm{p}<.001)$ and is part of the core model, but there is also a direct effect of different recycling options. The first item asks about the frequency of recycling if there were only one drop-off location in town. This resulted in $30 \%$ of respondents stating that they would "usually" or "always" recycle. The second item asking about recycling frequency if there were multiple locations across town resulted in about $66 \%$ of participants stating that they would 'usually' or 'always' recycle. This level of recycling options corresponds to the current situation in the city where the respondents live, and is in line with the frequencies of the behavioral intention of participants to recycle CFLs. The third item asks about recycling frequency in a hypothetical case of being able to recycle at all stores that sell CFLs. In this condition, nearly $90 \%$ of participants reported that they would "usually" or "always" recycle CFLs.

\section{Discussion}

Understanding the influences on consumer behavior in a condition of environmental trade-offs was the purpose of this study. It was expected that the Theory of Reasoned Action would be useful in understanding the influences of attitudes and subjective norms on behavioral intentions. The case of CFLs provides a good example to study the additional impacts of concern for potential mercury pollution influencing recycling weighed against the potential of energy savings from the efficiency of this type of light. The findings show that a core model explains the variance in the intention to recycle well.

\subsection{Managerial Implications}

The most powerful predictor is the subjective norm of perceived behavior in the peer group, here friends and family. This is a moderate to high predictor with a Beta of .661. This demonstrates how important it is for consumers to hear about the need to recycle from peers. A possible way to use this finding to improve recycling rates is using social media to spread recycling behavior as the norm and generate $\mathrm{C} 2 \mathrm{C}$ communication for recycling of CFLs. Examples could be to provide a badge or a public "thank you" message on one of the social networks for recycling. A possible implementation could utilize a QR-code at the place of recycling that can be read by a smartphone or use a location-based social network that allows check-ins into recycling locations. This rewards the desired behavior by increasing the visibility to friends and family, the reference group, and at the same time reinforces the behavior as the norm among the reference group.

The second interesting result is that, contrary to expectations, the attitude towards mercury is not significantly correlated with the intention to recycle CFLs. However, the attitude towards the overall environmental friendliness of CFLs, which gives consumers' weighted opinion on different areas like mercury content and energy savings, is correlated with the intention to recycle, however this correlation is negative. It is curious that this correlation is negative given that overall CFLs are indeed net-positive for the environment even when taking the mercury into account. It was expected that participants who are more likely to show environmental-friendly intentions, like the recycling of CFLs, would be able to recognize the positive environmental impact of CFLs and, 
accordingly, that higher recycling intentions would be related to a high opinion of the environmental friendliness of CFLs. A clue to understanding this result is found in the low correlation of the intention to recycle with the attitude towards mercury. This somehow paradoxical result can be explained by postulating that knowledge about mercury content is diffuse. It has tarnished the image of the environmental friendliness of CFLs but many consumers are likely not aware of the specific reason, i.e. the mercury content, for their negative attitude. Accordingly, this means that a better explanation of the facts, the net-positive impact of CFLs, is advisable while being candid about the mercury. However, going forward, the negative image of CFLs may be improved by communicating the advances of so called "green" CFLs. Improvements in technology have allowed the reduction in mercury content from the current voluntary maximum commitment of $5 \mathrm{mg}$ to $1 \mathrm{mg}$ or less per light bulb (Li \& Jin, 2011). If properly communicated, these advances will enable marketers to significantly improve the environmental image of CFLs.

\subsection{Labeling Implications}

Furthermore, improved knowledge could be achieved by better labeling. Current mandatory labeling contains the following passage: "Contains Mercury-For more on clean up and safe disposal, visit epa.gov/cfl." (Rule Concerning Disclosures Regarding Energy Consumption and Water Use of Certain Home Appliances and Other Products Required under the Energy Policy and Conversation Act ("Appliance Labeling Rule"), 2013). First, this label does not contain a reminder to recycle even though further information available on the mentioned EPA website does. The reasoning for this is that consumers might be enticed to place CFLs in the normal recycling bins for paper, cans, glass, etc. (Appliance Labeling Rule, p. 41706). However, the importance of recycling should be part of the label because, on the one hand, it immediately reminds consumers of this infrequent action, and, on the other hand, it reduces negative perceptions about CFLs by counteracting possible fears of damaging the environment when utilizing CFLs by giving an option to neutralize any impact of the mercury content. If these matters are properly explained insofar that "special" recycling is necessary for CFLs, confusion for consumers can be avoided while improving sustainability of CFLs. Second, the net mercury reduction for the average national electricity mix over the lifetime of the CFL is not part of the label. Ideally this should be visualized to educate consumers about the net positive impact of CFLs with regard to mercury emissions even if, for whatever reason, recycling is not an option for this particular consumer.

An improved label goes along with providing a positive message that recycling is the right thing to do. By advertising recycling on packaging, the attitude towards the recycling of CFLs would be reinforced. According to the results of this study, this should deliver the second highest returns for recycling intentions according to a beta-weight of .417. Manufacturers should consider adding this kind of information next to the official label. From a regulatory perspective adding this information is permitted as long as the mandatory label is still included (Appliance Labeling Rule, 41708). Apart from labeling, other avenues such as public service announcements (PSAs) on radio or TV would also be a viable option to potentially improve knowledge, attitudes, and consequently, CFL recycling rates.

\subsection{Policy Implications}

The convenience of recycling CFLs is the last relevant area where a recommendation can be made. The attitude towards the number of available sites to recycle CFLs is one of the significant antecedents and part of the core model. Furthermore, specific items exploring the impact of differing recycling availability levels clearly indicated that making recycling more convenient will increase the intention to recycle. Offering store-return recycling for CFLs might be an option. A comparable store-return system exists, for example, for batteries in Germany, or for glass bottles in certain US states.

\subsection{Limitaions and Future Research}

The model's predictive power was significantly improved by adding past behavior, as expected. Thus, the core model as well as the extended model do not seem to cover all the salient variables that influence the intention to recycle CFLs. A variety of models and approaches have been suggested to address this "attitude-behavior gap" (Kollmuss \& Agyeman, 2002). Further research could look into additional beliefs or expand the number of attitudes or norms that may influence recycling intentions. Another option would be to look at the theory of planned behavior which includes control beliefs into its framework.

In this study, the dependent variable, "Behavioral Intention to Recycle CFLs" was self-reported rather than measuring actual recycling behavior. Although correlations between intentions and behavior in the field of environmental behavior have been estimated at .54 (see for example the 2009 meta-analysis by Schwenk and Moser), there are other factors that influence the unexplained variance. Future studies, therefore, should measure actual recycling behavior if possible to get a more accurate estimate of the influence of the factors identified in 
this study.

Furthermore, the results presented here reflect attitudes and behavior in a specific regulatory environment. It would be useful to compare results from other geographical locations under various regulatory requirements for recycling. It is likely that differences in regulation and recycling history and norms will also impact behavioral intentions.

\section{Conclusion}

The CFL industry has incentives to increase the recycling rates of their products. Increased recycling rates means avoiding possible legislation related to mandatory recycling which could result in lower demand for CFLs by consumers. Other potential legislation might involve requiring manufacturers to receive and process CFLs, returned to retail sites. This would result in significant compliance costs for manufacturers. Another possible disadvantageous situation would occur if low recycling rates lead to a lowering of the allowed mercury content in CFLs. Therefore, a proactive behavior will benefit manufacturers by helping to avoid stricter government regulation. Sustainability over the complete life cycle is a relevant topic especially for a 'green' product that is sensitive to accusations of 'green-washing'. Accordingly, initiatives like lamprecycle.org have been funded by members of the National Electrical Manufacturers Association (NEMA) in the lighting business. Whitepapers published by NEMA concerning the topics of CFLs, recycling, mercury, and possible legislation in this area prove the importance of increased recycling rates to producers (National Electrical Manufacturers Association, $2005,2007,2008,2012$ ). This study provides new insights into consumer behavior that has actionable implications for the industry. Manufacturers should consider a greater role, for example funding social media activities, changes in labeling and other marketing communications such as those proposed above. Increased activity in improving recycling rates by taking the current research results into account is in the association's best interest.

\section{References}

Ajzen, I. (2002). Residual effects of past on later behavior: Habituation and reasoned action perspectives. $\begin{array}{llll}\text { Personality and Social Pychology Review, } & \text { 6(2), }\end{array}$ http://dx.doi.org/10.1207/S15327957PSPR0602_02

Ajzen, I., \& Fishbein, M. (1980). Understanding attitudes and predicting social behavior. Englewood Cliffs, NJ: Prentice-Hall.

Alvarez-Caicoya, J., Cosme-Torres, A. J., \& Ortiz-Rivera, E. I. (2011). Compact fluorescent lamps, an anticipatory mind to mercury. Potentials, IEEE, 30(1), 35-38. http://dx.doi.org/10.1109/MPOT.2010.939762

Appliance Labeling Rule (Final rule; opportunity for comment). (2010). Federal Register 75:137. (to be codified at 16 C.F.R. pt. 305).

Biswas, A., Licata, J. W., McKee, D., Pullig, C., \& Daughtridge, C. (2000). The recycling cycle: An empirical examination of consumer waste recycling and recycling shopping behaviors. Journal of Public Policy \& Marketing, 19(1), 93-105. http://dx.doi.org/10.1509/jppm.19.1.93.16950

California Department of Resources Recycling and Recovery. (2012, September 19). Fluorescent lamps and tubes: Waste prevention information. Retrieved June 13, 2013, from http://www.calrecycle.ca.gov/reducewaste/fluoreslamps/

Dahab, D. J., Gentry, J. W., \& Su, W. (1995). New ways to reach non-recyclers: An extension of the model of reasoned action to recycling behaviors. Advances in Consumer Research, 22, 251-256.

Dunmire, C., Calwell, C., Jacob, A., Ton, M., Reeder, T., \& Fulbright, V. (2003, May 30). Mercury in fluorescent lamps: Environmental consequences and policy implications for NRDC. Retrieved from http://www.bvsde.paho.org/bvsaia/fulltext/NRDCMercury.pdf

Earth911. (n.d.). CFLs near Omaha - recycling centers - Earth911.com. Retrieved June 16, 2013, from http://search.earth911.com/?what $=$ CFLs\&where $=$ Omaha\&list_filter $=$ all\&max_distance $=25 \&$ family_id $=\& l a$ titude $=\&$ longitude $=\&$ country $=\&$ province $=\&$ city $=$

Goldenhar, L. M., \& Connell, C. M. (1993). Understanding and predicting recycling behavior: An application of the theory of reasoned action. Journal of Environmental Systems, 22(1), 91-103. http://dx.doi.org/10.2190\%2F92KU-NXLT-XC32-RHD6

Hale, J., Householder, B., \& Greene, K. (2002). The theory of reasoned action. In J. Dillard \& M. Pfau (Eds.), 
The persuasion handbook: Developments in theory and practice (pp. 259-287). Thousand Oaks, CA: SAGE Publications, Inc. http://dx.doi.org/10.4135/9781412976046.n14

Hawkins, D. I. (2004). Consumer behavior: Building Marketing Strategy (9th ed.). Boston: McGraw-Hill Irwin.

Kollmuss, A., \& Agyeman, J. (2002). Mind the Gap: why do people act environmentally and what are the barriers to pro-environmental behavior? Environmental Education Research, 8(3), 239-260. http://dx.doi.org/10.1080/13504620220145401

Li, Y., \& Jin, L. (2011). Environmental release of mercury from broken compact fluorescent lamps. Environmental Engineering Science, 28(10), 687-691. http://dx.doi.org/10.1089/ees.2011.0027

Lindquist, J. D., \& Sirgy, M. J. (2006). Shopper, buyer, and consumer behavior: Theory, marketing, applications, and public policy implications. Cincinnati, Ohio: Atomic Dog Publishing.

Mercury-Containing Products That Are Hazardous Wastes When Discarded, 22 C.C.R. $§ 66261.50$ (2013).

Nameghi, E. E. M., \& Shadi, M. A. (2013). Affective and cognitive: Consumers attitude toward practicing green (reducing, recycling \& reusing). International Journal of Marketing Studies, 5(1), 157-164. http://dx.doi.org/10.5539/ijms.v5n1p157

National Electrical Manufacturers Association. (2005, March). Fluorescent and other mercury—containing lamps and the environment. Retrieved from http://www.nema.org/Policy/Environmental-Stewardship/Lamps/Documents/Lamp\%20Brochure.pdf

National Electrical Manufacturers Association. (2007, September). Manufacturer take-back of lamps. Retrieved from

http://www.nema.org/Policy/Environmental-Stewardship/Lamps/Documents/Manufacturer_Take_Back_09_ 07.pdf

National Electrical Manufacturers Association. (2008, October). Recycling household CFLs. Retrieved from http://www.nema.org/Policy/Environmental-Stewardship/Lamps/Documents/Recycling_Household_CFLs.p df

National Electrical Manufacturers Association. (2010, October 4). 2010 NEMA voluntary commitment on mercury in compact fluorescent lamps. NEMA. Retrieved June 13, 2013, from http://www.nema.org/Policy/Environmental-Stewardship/Lamps/Pages/CFL-Mercury.aspx

National Electrical Manufacturers Association. (2012, October). Lamp industry product stewardship—a record of environmental accomplishment. Retrieved from https://www.nema.org/Policy/Environmental-Stewardship/Lamps/Documents/Lamp\%20Industry\%20Produ ct $\% 20$ Stewardship\%20-\%20A\%20Record\%20of\%20Environmental\%20Accomplishment $\% 20 \% 20$ October \%202012.pdf

Nebraska Department of Environmental Quality. (2011, February). Bulb wastes. Retrieved from http://www.deq.state.ne.us/Publica.nsf/1ddd539d20b2b73986256870007b30a8/fce1200991a47ee5862577bc 0057b8bd/\$FILE/10-029.pdf

Park, J., \& Ha, S. (2012). Understanding pro-environmental behavior. International Journal of Retail \& Distribution Management, 40(5), 388-403. http://dx.doi.org/10.1108\%2F09590551211222367

Park, N. K., \& Lee, E. (2013). Energy-efficient lighting: Consumers' perceptions and behaviors. International Journal of Marketing Studies, 5(3), 26-35. http://dx.doi.org/10.5539\%2Fijms.v5n3p26

Rule Concerning Disclosures Regarding Energy Consumption and Water Use of Certain Home Appliances and Other Products Required under the Energy Policy and Conversation Act ("Appliance Labeling Rule"), 16 C.F.R. § 305.15 (b) (viii) (2013).

Schultz, P. W., \& Oskamp, S. (1996). Effort as a moderator of the attitude-behavior relationship: General environmental concern and recycling. Social Psychology Quarterly, 59(4), 375. http://dx.doi.org/10.2307/2787078

Schwenk, G., \& Moser, G. (2009). Intention and behavior: A Bayesian meta-analysis with focus on the Ajzen-Fishbein Model in the field of environmental behavior. Quality and Quantity, 43, 743-755. http://dx.doi.org/10.1007/s11135-007-9162-7

Standards for Universal Waste Management, 40 C.F.R. § 273.9. (2012).

U.S. Census Bureau. (2013, March). Table 1. Annual Estimates of the Population of Metropolitan and 
Micropolitan Statistical Areas: April 1, 2010 to July 1, 2012 (CBSA-EST2012-01). Retrieved from http://www.census.gov/popest/data/metro/totals/2012/tables/CBSA-EST2012-01.xls

US EPA. (2013, May 10). Frequent Questions about Regulations that Affect the Management and Disposal of Fluorescent Light Bulbs and other Mercury-Containing Light Bulbs (Lamps). Overviews \& Factsheets. Retrieved June 13, 2013, from http://www.epa.gov/osw/hazard/wastetypes/universal/lamps/faqs.htm

US EPA. (n.d.). How clean is the electricity I use?-Power Profiler. Retrieved June 16, 2013, from $\mathrm{http}: / / \mathrm{www}$.epa.gov/cleanenergy/energy-and-you/how-clean.html

Wagner, T. P. (2009, September). Household compact fluorescent light (CFL) recycling in Maine. Retrieved from http://www.usm.maine.edu/ esd/fac/documents/twFINALreportsept_12_2009.pdf

Wagner, T. P. (2011). Compact fluorescent lights and the impact of convenience and knowledge on household recycling rates. Waste Management, 31(6), 1300-1306. http://dx.doi.org/10.1016/j.wasman.2011.01.017

WasteCap Nebraska. (n.d.). Locations|WasteCap Nebraska. Retrieved June 16, 2013, from http://www.wastecapne.org/anotherbrightidea/locations/

White, K. M., \& Hyde, M. K. (2012). The Role of Self-Perceptions in the Prediction of Household Recycling Behavior in Australia. Environment \& Behavior, 44(6), 785-799.

\section{Copyrights}

Copyright for this article is retained by the author(s), with first publication rights granted to the journal.

This is an open-access article distributed under the terms and conditions of the Creative Commons Attribution license (http://creativecommons.org/licenses/by/3.0/). 